\title{
An Analysis of a Crucible Survival and a Bead Fragments Excavated at Iksan Wanggung-ri Site in Korea
}

\author{
Gyu-Ho Kim ${ }^{1}$ | Eun-A Kim \\ Dept. of Conservation Science for Cultural Properties, Kongju National University, Gongju, 32588, Korea \\ ${ }^{1}$ Corresponding Author: kimgh@kongju.ac.kr, +82-41-850-8544
}

\begin{abstract}
The extensive archaeological remains at the Baekje Kingdom site of Wanggung-ri, Iksan, in the South Jeolla Province, Korea, include a seventh century workshop area that was later covered by the construction of a Buddhist temple. Remains of glass, gold, and bronze artefacts, and the ceramic crucibles used in the working of these materials, provide evidence for a multi-craft, high-temperature technology. We will report the results of both chemical compositional and lead isotope analyses for Wanggung-ri glass, which is among the earliest lead-silica glass type in East Asia, as well as review the evidence for primary glass production at Wanggung-ri.
\end{abstract}

Key Words: Lead glass, Primary glass production, Crucible, Lead isotope, Wanggung-ri,

\section{INTRODUCTION}

The purpose of this study is to summarize the research results on glasses and crucibles excavated from the Wanggung-ri site near Iksan in Jeollabukdo Province of South Korea. Wanggung-ri is well known for early primary glass production in ancient Korea, and we will examine glass manufacturing techniques used in this period(Kim et al., 2006).

Since 1989, the Buyeo National Research Institute of Cultural Heritage has been conducting excavations of Iksan Wanggung-ri archaeological site(Historical Landmark Number 208), where many palace-related archeological remains from the Baekje period(ca 6-7c. CE)(palace walls, stone structures, large lavatory sites, gardens, roof-tile based structures and craftwork manufacturing sites) and templerelated remains from the Unified Silla period(ca late $7 \mathrm{c}$ to 10c CE), e.g., Keumdang-ji and Kangdang-ji(main temple shrines) associated with Wanggung-ri Five Story Stone Pagoda(National Treasure Number 289), have been discovered. One of the more important findings of Wanggung-ri excavations was the discovery of a large-scale manufacturing facility in the northwest area of Wanggung-ri site. This facility consists of a manufacture scrap site, the burnt-clay site, and the burnt-clay scrap site. The manufacture scrap site is $14 \mathrm{~m}$ in length from north to south and $9.4 \mathrm{~m}$ in width from west to east. Many fragments of metal- and glass-working ceramic crucibles, roof tiles, charcoal, and various slags were excavated from this site. The burnt-clay site and burnt-clay scrap site are located in the southwest of the manufacture scrap site. From the burnt-clay site, many manufacturing related artifacts, e.g., crucibles were excavated. From the burnt-clay scrap site were excavated large quantities of metal-working crucibles, crucible lids, glass fragments(including green, jade-green, blue and yellow glass beads) and various gold products such as gold beads, thread and nails.

The archaeological remains and artifacts excavated from Wanggung-ri site make us speculate that the site was a large-scale manufacturing facility for gold, metal and glass products. What is unique about the Wanggung-ri site, however, is that all the excavated artifacts were either raw materials or semi-finished products, with few finished products excavated from the site. Therefore, it is necessary to investigate the nature of the manufacturing facility at Wanggung-ri site by examining the functionalities of each excavated artifact and investigating production techniques and distribution process associated with raw materials and finished products. Although there were some sporadic 
attempts in the past on applying scientific analysis to manufacturing-related artifacts, no attempt has been made yet to identify the general nature of the manufacturing site itself. Accordingly, a consensus was formed in 2004 voicing the need for starting more cooperative research efforts to facilitate systematic scientific analyses of the subject.

In this study, I present my research results on the nature of the Wanggung-ri manufacturing facility. In the first part of my research, I focused on gathering basic data from all the artifacts excavated from Wanggung-ri site to which non-destructive method could be applied. Then, using non-destructive methods, I examined the raw material characteristics of the excavated gold, metals and glasses. Also, I investigated the characteristics of the crucibles that were used to manufacture them in order to describe the relationship among various artifacts excavated from the manufacture site. In the second part of my research, from the glass fragments and crucibles excavated from Wanggung-ri site, I chose the artifacts which contained lead and from which specimen sampling was possible. Using these data, I tried to trace their relationship to a lead production site and suggested a relationship between lead glasses and the glass crucibles that were used to manufacture them. Finally, putting all the results together, I will present the results of chemical composition and isotope analysis for glass beads and crucibles excavated from the Wanggung-ri site. In doing so, I will try to establish scientific information regarding supply and distribution of raw materials for lead-related products that are being found in the Baekje region.

\section{INTRODUCTION OF THE WANGGUNG-RI ARCHAEOLOGICAL}

Iksan Wanggung-ri archaeological site(Historical Landmark Number 408) is located in 634 Wanggung-ri, Wanggungmyun, Iksan City of Jeonrabuk-do Province. It is located on the low hill left of the National Highway 1, about $4 \mathrm{~km}$ south of Keumma-myun to the direction of Jeonju City. The historical records - History of the Three Kingdoms(Samguk- sagi), Spiritual Experience of Guan-In Bodhitsavaa(KwanseumEungheumgi), New and Expanded Geography of Korea (Shinjeung-Dongukyeojiseugram) and The Book of Keumma (Keumma-ji) - tell us that Wanggung-ri site had been in use from Baekje to Koryo period. The excavation of the site has been in progress since 1989 to the present. Inside the palace wall(492 $\mathrm{m}$ in length from north to south and $234 \mathrm{~m}$ in width from west to east) have been found many palacerelated archaeological remains from the Baekje period stone structures, large lavatory sites, gardens, roof-tile based structures, scrap manufacture sites and other artifacts - and temple-related remains from the Unified Silla period such as Keumdang-ji and Kangdang-ji(main temple shrines) related to the Five Story Stone Pagoda(National Treasure Number 289) at the Wanggung-ri site. The palace is divided into north and south in a two to one ratio in terms of land area, and separated by the large-scale Fourth East-West Stone Drainage Channel. In the northwest area, a manufacture scrap site, burnt-clay scrap site, burnt-clay site and other manufacturing related facilities have been discovered. The manufacture scrap site is located in a flat land area between the western palace wall and the rolling hill in the east that extends in from north to south. It is $14 \mathrm{~m}$ in length from north to west, $7.4 \mathrm{~m}$ in width from west to east, and 30 4 cm in depth. When this site was excavated, large quantities of metal fragments, glass crucibles, roof tiles, charcoal, burnt-clay clumps, metal slag and other manufacturing waste were found scattered around along with burnt-clay. In particular, slightly angled or round-shape artifacts that are now speculated to be the remnants of furnace walls were found stuck in the ground, suggesting the presence of an active manufacturing site. The burnt-clay site was found in the south of the manufacture scrap site. Extending south in parallel to the eastern palace wall in a reverse-S shape, it extends perpendicular to the East-West Stone Drainage Channel. It is $77 \mathrm{~m}$ in length, $50 \sim 60 \mathrm{~m}$ in width and 20 50 $\mathrm{cm}$ in depth. When it was discovered, the burnt-clay site was filled with sand-grain quality burnt-clay and other manufacturing-related artifacts in large quantity. The burnt-clay scrap site extends in a north-south direction from the north of the East-West Stone Structure Drainage 
Channel. The site is not clearly defined in terms of demarcations and the research could not confirm the presence of any facility that could be viewed as a manufacture site. However, it is speculated that there had existed a structure here, the fact which is evidenced by the presence of burnt-clay with black-reddish color(the evidence of having been heat-treated), various types of crucibles and crucible lids discovered from the charcoal layer, roof tile fragments, inkstones and pottery. In conclusion, the discovery of various manufacturing-related artifacts along with gold, glass fragments, various crucibles, slag and air ventilation pipes(tuyeres) allows us to conclude that Wanggung-ri site was a large-scale manufacturing site that produced various types of artifacts.

\section{RESEARCH RESULTS}

\subsection{Glass bead fragments}

In this research, I investigated the total of 73 glass bead fragments randomly selected from the manufacture site, which is speculated to be the lower part of Kangdang-ji (main temple shrine) of the Unified Shilla period. I examined their visible exterior characteristics, measured their specific gravity, and conducted chemical composition analysis using non-destructive methods.

The analysis result shows that the glass bead fragments consisted of 60 lead glasses, 8 alkaline glasses, and 5 quartz/feldspar related glasses(Figure 1). The samples were based on random selection and therefore the result is not representative of the general characteristics of the glass

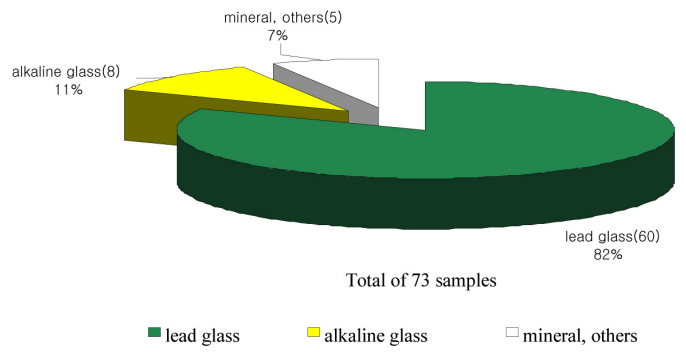

Figure 1. Analysis result of glass fragments excavated from Wanggung-ri site. beads excavated from Wanggung-ri site. However, what is interesting here is the presence of alkaline glasses. So far, all the glasses excavated from Wanggung-ri site have been lead glasses. The discovery of alkaline glass now suggests the possibility that various glasses other than lead glass were used and possibly produced at Wanggung-ri.

\subsubsection{Lead glasses}

We analyzed the total of 60 lead glasses in this research. Most of them were glass fragments from manufacturing related facilities but 12 of them were excavated from the manufacture site speculated to be the lower part of Kangdang-ji(main temple shrine) of the Unified Shilla period. Figure 2 shows lead glasses in various weathering conditions. Figure 2 (1) (4) lists them in the order of the degrees of weathering effect. Figure 2 (5) and (6) shows the front and back of the same lead glass sample, one side weathered and the other side un-weathered. The surface of green-color type lead glass gradually wears out through the weathering process and eventually becomes white. It also
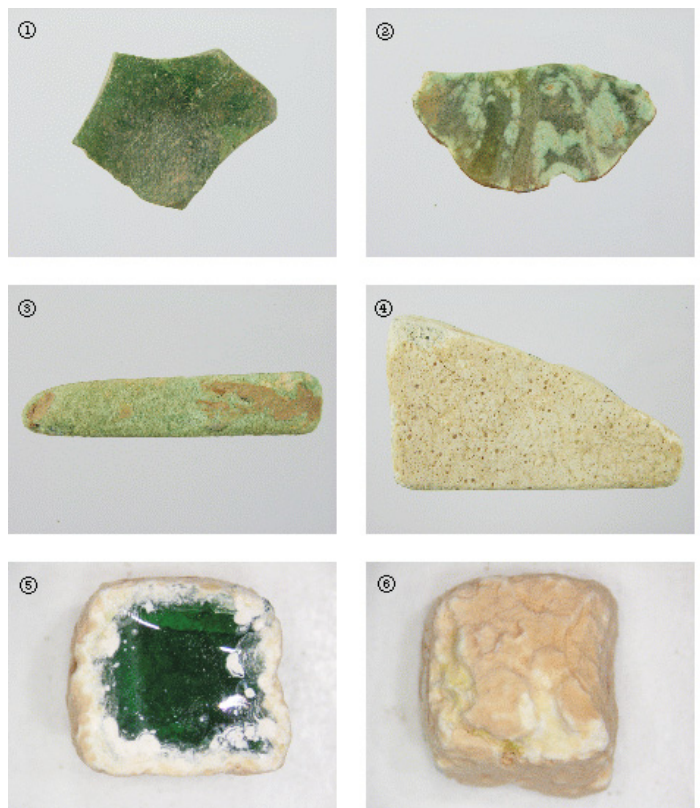

Figure 2. Lead glass in different stages of weathering process. (1): GL28-5, (2): GL10, (3): GL28-6, (4): GL28-7, (5): GL29-5 front $(\times 6.3)$, 6): GL29-5 back $(\times 6.3)$. 
builds a layer to form a separate weathering layer, which exfoliates and becomes increasingly granular, eventually becoming like powder. The chemical composition of the glass surface shows differences from that of the inner glass due to weathering effect.

Table 1 compares the chemical composition of lead glass produced by non-destructive and destructive methods. It shows the average composition ratio for 5 major elements normalized to $100 \%$. As shown in Table 1 , the sample analyzed using X-ray fluorescence spectrometry(SE2000A, Seiko Ltd., Japan)(non- destructive method) shows the compositional ratio of $7: 3$ between $\mathrm{SiO}_{2}$ and $\mathrm{PbO}$, although the ratio varies to a minor extent depending on the presence of weathering effect. However, the result of electron probe microanalysis(LV-5400, Jeol Ltd., Japan)(destructive method) shows a 3:7 compositional ratio, demonstrating the limitation of using non-destructive methods to analyze the chemical composition of lead glass. In the case of lead glass, the weathering layer formed by interaction with the soil in its burial environment prevents the use of non-destructive methods from being effective. It proves that using such a method as XRF would produce a different, and misleading, chemical composition of major elements and this is demonstrated in this example, where analysis based on the non-destructive method produced a lower composition ratio for lead $(\mathrm{PbO})$ and a higher ratio for silica $\left(\mathrm{SiO}_{2}\right)(\mathrm{Kim}, 2002)$.

\subsubsection{Alkaline glasses}

We used the total of 8 alkaline glasses for our analysis and the results of chemical composition analysis and specific gravity measurement are as shown below(Table 2 ).

GL30-6 is double-sided glass and it was separated into two parts - interior and exterior - for this study. GL30-8 was too small to calculate specific gravity. Based on these results, we compared the relative content of $\mathrm{K}_{2} \mathrm{O}$ and $\mathrm{Na}_{2} \mathrm{O}$

Table 1. Comparing lead glass compositional ratio produced by different analysis methods

\begin{tabular}{|c|c|c|c|c|c|c|c|}
\hline Grouping & $\mathrm{SiO}_{2}$ & $\mathrm{PbO}$ & $\mathrm{Al}_{2} \mathrm{O}_{3}$ & $\mathrm{Fe}_{2} \mathrm{O}_{3}$ & $\mathrm{CuO}$ & Total & etc \\
\hline \multicolumn{8}{|c|}{ XRF-weathering samples(7) } \\
\hline Average & 74.7 & 20.7 & 3.7 & 0.8 & 0.1 & 100.0 & \\
\hline Stdev & 5.1 & 3.6 & 3.1 & 0.4 & 0.8 & 0.0 & \\
\hline \multicolumn{8}{|c|}{ XRF-no weathering samples(53) } \\
\hline Average & 64.4 & 32.5 & 2.3 & 0.6 & 0.2 & 100.0 & \\
\hline Stdev & 8.0 & 8.6 & 3.1 & 0.8 & 0.1 & 0.0 & \\
\hline \multicolumn{8}{|c|}{ EPMA samples(9) } \\
\hline Average & 27.2 & 72.1 & 0.3 & 0.2 & 0.3 & 100.0 & \\
\hline Stdev & 0.6 & 0.6 & 0.1 & 0.1 & 0.1 & 0.0 & \\
\hline
\end{tabular}

Table 2. The result of chemical composition analysis for alkaline glasses from Wanggung-ri site

\begin{tabular}{|c|c|c|c|c|c|c|c|c|c|c|c|c|c|c|c|}
\hline \multirow{2}{*}{$\begin{array}{c}\text { Analysis } \\
\text { No. }\end{array}$} & \multirow{2}{*}{$\begin{array}{c}\text { Specific } \\
\text { gravity }\end{array}$} & \multirow{2}{*}{$\begin{array}{c}\text { Analyzed } \\
\text { location }\end{array}$} & \multicolumn{13}{|c|}{ Composition (\%) } \\
\hline & & & $\mathrm{SiO}_{2}$ & $\mathrm{Na}_{2} \mathrm{O}$ & $\mathrm{K}_{2} \mathrm{O}$ & $\mathrm{CaO}$ & $\mathrm{Al}_{2} \mathrm{O}_{3}$ & $\mathrm{MgO}$ & $\mathrm{Cl}$ & $\mathrm{TiO}_{2}$ & $\mathrm{MnO}$ & $\mathrm{Fe}_{2} \mathrm{O}_{3}$ & $\mathrm{CuO}$ & $\mathrm{PbO}$ & $\mathrm{BaO}$ \\
\hline GL11 & 2.49 & & 72.6 & 0.63 & 4.23 & 7.28 & 9.65 & 2.06 & 1.41 & 1.02 & 0.06 & 1.08 & 0.01 & 0.00 & 0.00 \\
\hline GL18 & 2.81 & & 62.9 & 8.73 & 2.32 & 6.93 & 4.36 & 1.37 & 2.03 & 1.33 & 0.06 & 1.24 & 0.02 & 8.68 & 0.02 \\
\hline GL20 & 2.38 & & 77.1 & 1.18 & 2.25 & 4.28 & 5.13 & 0.20 & 2.88 & 3.57 & 0.10 & 2.10 & 1.15 & 0.02 & 0.02 \\
\hline GL29-1 & 2.51 & & 70.3 & 9.76 & 1.87 & 12.7 & 3.06 & 0.13 & 1.02 & 0.63 & 0.03 & 0.37 & 0.00 & 0.02 & 0.10 \\
\hline GL30-4 & 2.61 & & 63.3 & 10.4 & 4.80 & 7.67 & 4.41 & 2.67 & 1.78 & 2.14 & 0.10 & 1.54 & 1.24 & 0.00 & 0.00 \\
\hline GL30-6 & 2.53 & Interior & 61.5 & 12.7 & 4.72 & 7.94 & 3.62 & 2.88 & 1.80 & 1.91 & 0.08 & 1.51 & 1.30 & 0.02 & 0.01 \\
\hline GL30-6 & & Surface & 68.4 & 3.71 & 4.81 & 7.27 & 4.92 & 3.45 & 2.03 & 2.30 & 0.10 & 1.95 & 0.59 & 0.40 & 0.02 \\
\hline GL30-8 & & & 75.0 & 0.80 & 2.79 & 5.04 & 0.59 & 0.18 & 5.86 & 5.72 & 0.18 & 2.44 & 1.35 & 0.01 & 0.04 \\
\hline GL30-9 & 2.46 & Green & 67.9 & 6.35 & 1.49 & 2.23 & 6.08 & 0.51 & 2.21 & 3.05 & 0.09 & 1.70 & 1.10 & 7.16 & 0.10 \\
\hline
\end{tabular}


using $5 \%$ as the critical value in order to obtain glass categorization using the fusing agents. Soda glass has $\mathrm{Na}_{2} \mathrm{O}$ content greater than $5 \%$ and there were five of them, including the interior side glass of GL30-6(GL30-6a). The rest of the samples had $\mathrm{K}_{2} \mathrm{O}$ content higher than $\mathrm{Na}_{2} \mathrm{O}$ but did not have the chemical composition that could clearly identify them as potash glass. This is due to the limitation of non-destructive method that allows us to examine only the surface of samples, which are affected by the weathering process in the captive environment. Therefore, it was difficult to obtain the precise chemical composition of the samples. However, we speculate that these glasses are more likely soda glasses than potash glasses.

With this in mind, the alkaline glasses were further examined, and they turned out to be mostly soda glasses - but with different content of lime $(\mathrm{CaO}$, the stabilizing agent $)$, in comparison to other soda glasses discovered in the Baekje area. The soda glasses excavated from the King Muryeong Tomb and Naju Bokamri Kobun Number 3 have $\mathrm{CaO}$ content less than $5 \%$ while the alkaline glass discovered in Wanggung-ri have $\mathrm{CaO}$ content greater than $5 \%$ (Kim, 2013). We still need further analyses on this topic but it appears certain that the 8 alkaline glasses from Wanggung-ri site are soda glasses with unique chemical composition that have not been found in Baekje area to this date.

\subsubsection{Minerals(others)}

The analysis result for the 5 non-glass samples that were chosen from 73 glass bead samples are shown in Table 3 below.

GL1 and GL27 were beads with $95 \% \mathrm{SiO}_{2}$ in content that turned out to be made out of quartz. Each sample of
GL16 showed similar chemical composition and they are presumed to be of identical origin(Figure 3). What is interesting about them is that they have $\mathrm{TiO}_{2}$ content greater than $20 \%$. Also, they were lighter than water and, therefore, their specific gravity could not be measured. GL25 has $14 \% \mathrm{CaO}$ content and, like GL16, we need further investigations in order to determine their identities.

\subsection{Crucibles}

Crucibles of similar types are being excavated from the Wanggung-ri site, the Mireuk-sa Temple site as well as from Kwanbuk-ri, Neungsan-ri and Ssangbuk-ri in Buyeo. However, there has been no systematic analysis on crucible contents and the basic data is very lacking. As to the crucibles excavated from Wanggung-ri site, there has been some scientific data presented in a report published in 2002, but they were limited to few gold and glass crucibles, leaving the need for comprehensive research and analysis intact.

The samples used for this analysis included all excavated crucibles except for glass crucibles that could only be analyzed with the naked eye. Assuming that the crucibles had smelting materials left in the interior part, I compared the chemical elements of the clay from the interior and
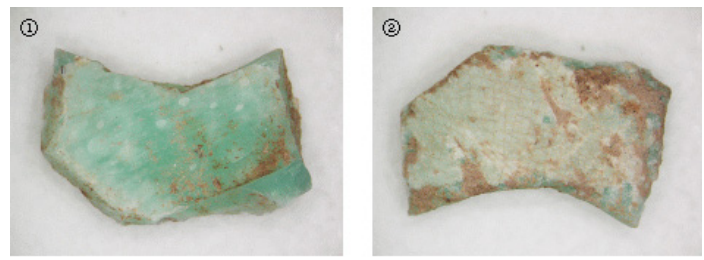

Figure 3. Examples of other minerals. (1), (2): GL16-1, front and back.

Table 3. Compositional analysis result of minerals and other materials excavated from Wanggung-ri site

\begin{tabular}{|c|c|c|c|c|c|c|c|c|c|c|c|c|c|c|c|}
\hline \multirow{2}{*}{$\begin{array}{c}\text { Analysis } \\
\text { No. }\end{array}$} & \multirow{2}{*}{$\begin{array}{l}\text { Specific } \\
\text { gravity }\end{array}$} & \multicolumn{13}{|c|}{ Analysis result (\%) } & \\
\hline & & $\mathrm{SiO}_{2}$ & $\mathrm{Na}_{2} \mathrm{O}$ & $\mathrm{K}_{2} \mathrm{O}$ & $\mathrm{CaO}$ & $\mathrm{Al}_{2} \mathrm{O}_{3}$ & $\mathrm{MgO}$ & $\mathrm{Cl}$ & $\mathrm{TiO}_{2}$ & $\mathrm{MnO}$ & $\mathrm{Fe}_{2} \mathrm{O}_{3}$ & $\mathrm{CuO}$ & $\mathrm{PbO}$ & $\mathrm{BaO}$ & \multirow[b]{2}{*}{ Quartz } \\
\hline GL1 & 2.50 & 94.5 & 0.03 & 0.24 & 0.13 & 3.42 & 0.29 & 0.44 & 0.56 & 0.03 & 0.36 & 0.03 & 0.01 & 0.00 & \\
\hline GL16-1 & $x$ & 53.3 & 1.01 & 1.46 & 0.56 & 10.1 & 0.54 & 4.09 & 26.3 & 0.23 & 2.45 & 0.02 & 0.00 & 0.00 & \\
\hline GL16-2 & $x$ & 58.2 & 0.36 & 1.22 & 0.45 & 12.3 & 1.19 & 3.29 & 20.9 & 0.36 & 1.71 & 0.02 & 0.00 & 0.01 & \\
\hline GL25 & 2.96 & 63.5 & 3.45 & 0.03 & 14.3 & 0.10 & 16.1 & 1.19 & 0.05 & 0.07 & 1.16 & 0.00 & 0.01 & 0.01 & \\
\hline GL27 & 2.63 & 94.5 & 0.00 & 0.04 & 0.16 & 3.37 & 0.30 & 0.55 & 0.77 & 0.01 & 0.28 & 0.03 & 0.00 & 0.00 & Quartz \\
\hline \multicolumn{16}{|c|}{ Total of 5 samples } \\
\hline
\end{tabular}


exterior part of the crucible and determined as the smelting material the element showing up relatively higher in content in the interior part. Using this method, I was able to identify the smelting materials for 71 crucibles. I am presenting the result for 86 samples in Figure 4 - the 71 samples discussed above and 10 additional samples randomly selected to determine the presence of lead glass and analyze the differences in chemical composition resulting from color differences.

The result shows that there were 11 gold crucibles, 60 copper alloy crucibles, 10 glass crucibles and 5 crucibles whose identity could not be determined. We will focus on

Table 4. Lead isotope values for glasses and crucible-attached glasses excavated from Wanggung-ri site

\begin{tabular}{|c|c|c|c|c|c|c|c|}
\hline No. & Sample & $206 \mathrm{~Pb} / 204 \mathrm{~Pb}$ & $207 \mathrm{~Pb} / 204 \mathrm{~Pb}$ & $208 \mathrm{~Pb} / 204 \mathrm{~Pb}$ & $207 \mathrm{~Pb} / 206 \mathrm{~Pb}$ & $208 \mathrm{~Pb} / 206 \mathrm{~Pb}$ & Etc \\
\hline 1 & YG1 & 17.569 & 15.635 & 38.984 & 0.8899 & 2.2189 & \\
\hline 2 & YG2 & 17.815 & 15.662 & 39.070 & 0.8792 & 2.1931 & \\
\hline 3 & YG3 & 17.802 & 15.656 & 39.051 & 0.8794 & 2.1936 & \\
\hline 4 & YG4 & 17.482 & 15.603 & 38.874 & 0.8925 & 2.2237 & \\
\hline 5 & YG5 & 17.544 & 15.631 & 38.968 & 0.8909 & 2.2211 & \\
\hline 6 & YG6 & 17.397 & 15.601 & 38.867 & 0.8967 & 2.2341 & \\
\hline 7 & YG7 & 17.341 & 15.595 & 38.848 & 0.8993 & 2.2402 & \\
\hline 8 & YG8 & 17.345 & 15.585 & 38.815 & 0.8985 & 2.2378 & \\
\hline 9 & YG9 & 17.820 & 15.659 & 39.056 & 0.8787 & 2.1917 & \\
\hline 10 & YG10 & 17.339 & 15.593 & 38.843 & 0.8993 & 2.2401 & \\
\hline 11 & YG11-1 & 17.346 & 15.604 & 38.879 & 0.8996 & 2.2414 & \\
\hline 12 & YG11-2 & 17.340 & 15.594 & 38.847 & 0.8993 & 2.2403 & \\
\hline 13 & YG12 & 17.344 & 15.597 & 38.856 & 0.8993 & 2.2403 & \\
\hline 14 & YG13 & 17.590 & 15.610 & 38.736 & 0.8874 & 2.2022 & \\
\hline 15 & YG14 & 17.344 & 15.601 & 38.870 & 0.8995 & 2.2411 & \\
\hline 16 & YG15-1 & 17.353 & 15.608 & 38.894 & 0.8994 & 2.2413 & \\
\hline 17 & YG15-2 & 17.346 & 15.597 & 38.858 & 0.8992 & 2.2402 & \\
\hline 18 & YG16 & 17.338 & 15.593 & 38.843 & 0.8993 & 2.2403 & \\
\hline 19 & YG17 & 17.340 & 15.594 & 38.848 & 0.8993 & 2.2403 & \\
\hline 20 & YG18 & 17.444 & 15.612 & 38.906 & 0.8950 & 2.2303 & \\
\hline 21 & YG19 & 17.747 & 15.642 & 39.072 & 0.8814 & 2.2016 & \\
\hline 22 & YG35-1 & 17.424 & 15.609 & 38.892 & 0.8958 & 2.2321 & \\
\hline 23 & YG35-2 & 17.421 & 15.609 & 38.897 & 0.8960 & 2.2328 & \\
\hline 24 & YG35-3 & 17.417 & 15.605 & 38.880 & 0.8959 & 2.2323 & \\
\hline 25 & YG36-1 & 17.344 & 15.596 & 38.847 & 0.8992 & 2.2398 & \\
\hline 26 & YG36-2 & 17.355 & 15.613 & 38.909 & 0.8996 & 2.2420 & \\
\hline 27 & YG37 & 17.847 & 15.669 & 39.092 & 0.8780 & 2.1904 & \\
\hline 28 & YG38-1 & 17.339 & 15.594 & 38.847 & 0.8993 & 2.2404 & \\
\hline 29 & YG38-2 & 17.336 & 15.590 & 38.834 & 0.8993 & 2.2400 & \\
\hline 30 & YG38-3 & 17.338 & 15.589 & 38.825 & 0.8991 & 2.2393 & \\
\hline 31 & YG39 & 17.586 & 15.632 & 34.595 & 0.8889 & 2.2152 & \\
\hline 32 & YG40-1 & 17.340 & 15.593 & 34.897 & 0.8993 & 2.2401 & \\
\hline 33 & YG40-2 & 17.340 & 15.595 & 34.904 & 0.8994 & 2.2404 & \\
\hline 34 & YG41 & 18.108 & 15.704 & 33.969 & 0.8673 & 2.1651 & \\
\hline 35 & YG42 & 18.111 & 15.699 & 33.935 & 0.8668 & 2.1637 & \\
\hline 36 & YG43 & 17.353 & 15.600 & 34.906 & 0.8990 & 2.2397 & \\
\hline 37 & YG44 & 17.345 & 15.601 & 34.925 & 0.8994 & 2.2408 & \\
\hline 38 & YG45 & 17.343 & 15.590 & 34.873 & 0.8989 & 2.2391 & \\
\hline \multicolumn{2}{|c|}{ Std err } & \pm 0.010 & \pm 0.010 & \pm 0.030 & \pm 0.0003 & \pm 0.0006 & \\
\hline
\end{tabular}


glass crucibles exclusively in this paper.

Glass crucibles are similar in shape to copper crucibles but do not have a mouth or lid. In terms of size, glass crucibles tend to be larger than gold crucibles(Figure 5). The qualitative analysis of glass materials left on the surface of crucibles confirms that they are lead glasses. Regardless of the type, material and color, copper was detected in most of them. Copper was used as the coloring material and it appears that the degree of oxidation has caused the differences in color.

\subsection{Lead isotope ratio}

The samples used for this analysis were glasses and glass remnants attached to the crucible walls excavated from the Wanggung-ri site. The large quantity of glasses and crucibles that seem to have been used for glass production were excavated from manufacture sites and from Kangdang-ji(main temple shrine) sites at Wanggung-ri site. From them, I chose 19 glasses and 11 crucibles for my isotope analysis(Table 4). In addition, I decided to use the

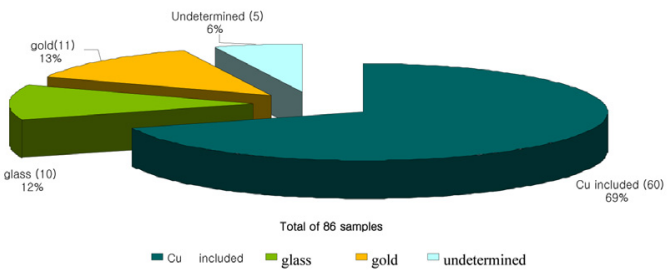

Figure 4. Distribution of raw materials used in crucibles excavated from Wanggung-ri site. glasses and crucible-attached glasses from Mireuk-sa Temple as comparison data(Table 5). I also included in this paper the analysis results on the glasses and crucibles excavated from Mireuk-sa Temple reported in 2001 Mireuk-sa Temple was built by the King Mu of Baekje and is considered one of the largest historical relics of the Baekje Kingdom along with Wanggung-ri(Kang et al., 2003). The research results collected from Wanggung-ri and Mireuk-sa Temple provide very useful information for understanding production and distribution of glasses in Baekje around the 7th century(Brill et al., 1967; Brill et al., 1979; Han and Kim, 2015).

According to the lead isotope ratio distribution map (Figure 6,7), the glasses and crucible-attached glasses from the Wanggung-ri site are distributed along the straight line within a narrow range. Also, the glasses excavated from Mireuk-sa Temple are distributed along the same area on the distribution map as the glasses from Wanggung-ri site.

The glass fragments excavated from the manufacture sites are distributed along the straight line. YG11 has greenish blue and red brown colors. These samples were
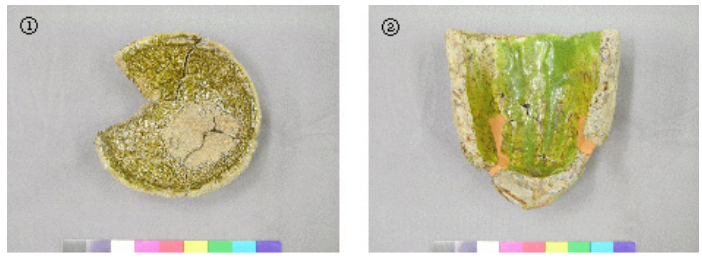

Figure 5. Examples of glass crucibles excavated from Wanggung-ri site.

Table 5. Lead isotope values for glasses and crucible-attached glasses excavated from Mireuk-sa Temple site

\begin{tabular}{|c|c|c|c|c|c|c|c|}
\hline No. & Sample & ${ }^{206} \mathrm{~Pb} /{ }^{204} \mathrm{~Pb}$ & ${ }^{207} \mathrm{~Pb} /{ }^{204} \mathrm{~Pb}$ & ${ }^{208} \mathrm{~Pb}^{1204} \mathrm{~Pb}$ & ${ }^{207} \mathrm{~Pb} /{ }^{206} \mathrm{~Pb}$ & ${ }^{208} \mathrm{~Pb} /{ }^{206} \mathrm{~Pb}$ & Etc \\
\hline 39 & MR1 & 17.720 & 15.636 & 34.368 & 0.8824 & 2.2001 & \\
\hline 43 & MR5 & 17.340 & 15.594 & 34.905 & 0.8994 & 2.2404 & \\
\hline 44 & MR6 & 17.521 & 15.613 & 34.637 & 0.8911 & 2.2206 & \\
\hline 45 & MR7 & 17.450 & 15.605 & 34.735 & 0.8942 & 2.2281 & \\
\hline 46 & MR8-1 & 17.699 & 15.637 & 34.413 & 0.8835 & 2.2028 & \\
\hline 47 & MR8-2 & 17.700 & 15.643 & 34.441 & 0.8838 & 2.2037 & \\
\hline 48 & MR8-3 & 17.703 & 15.642 & 34.432 & 0.8836 & 2.2033 & \\
\hline 49 & MR10 & 17.433 & 15.599 & 34.739 & 0.8948 & 2.2291 & \\
\hline 50 & MR11 & 17.441 & 15.614 & 34.803 & 0.8952 & 2.2311 & \\
\hline \multicolumn{2}{|c|}{ Std err } & \pm 0.010 & \pm 0.010 & \pm 0.030 & \pm 0.0003 & \pm 0.0006 & \\
\hline
\end{tabular}


named YG11-1 and YG11-2, respectively. Changes in color of glass are caused by a change in the arrangement of transition metal ions as a result of adding of foreign or impure materials, intentional or otherwise. The analysis result of YG11-1 and YG11-2 shows that, despite the color differences, their lead isotope ratios matched within the margin of errors. That is, the same raw materials were used for YG11 regardless of their color differences. Likewise, YG2-YG3-YG9, YG7-YG8-YG10-YG11-1-YG11-2, YG1-YG5 paired-groups were distributed within the margin of errors, respectively. This suggests the possibility that these samples were either different glass products made out of identical raw materials or a part of a single glass product. However, we must also keep in mind that, if glasses were made from the same crucible but were produced in a state where the raw materials were not mixed well, their isotope ratio could be different.

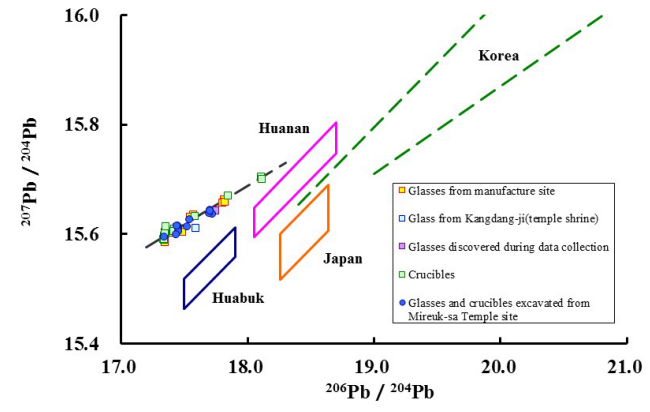

(a) ${ }^{207} \mathrm{~Pb} /{ }^{204} \mathrm{~Pb}-{ }^{206} \mathrm{~Pb} /{ }^{204} \mathrm{~Pb}$

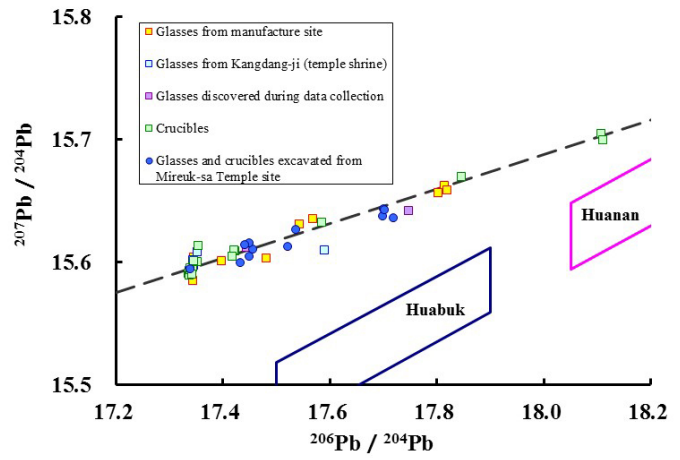

(b) Scale up (a) type

Figure 6. Lead isotope ratio $\left({ }^{207} \mathrm{~Pb} /{ }^{204} \mathrm{~Pb}-{ }^{206} \mathrm{~Pb} /{ }^{204} \mathrm{~Pb}\right)$ for glasses and crucibles excavated from Wanggung-ri and Mireuk-sa Temple sites.
The crucibles excavated from the Wanggung-ri site had glasses melted and attached to their interior and exterior. I collected some glass samples from the crucibles for analysis. Depending on the sample, we collected samples from many different areas of the same glass(YG35, YG36, YG38, YG40).

There were 10 glasses and crucibles excavated from Mireuk-sa Temple site. Among these, MR8 MR11 are crucible samples. In case of MR8, the samples were collected from the mouth and 3 different locations in the base. Like the glasses from the Wanggung-ri site, Mireuk-sa Temple glasses are distributed along the straight line in the distribution map. The samples from Mireuk-sa Temple tend to be heavily distributed around 4 major areas. MR8, the crucible sample and MR1, glass sample, are distributed in

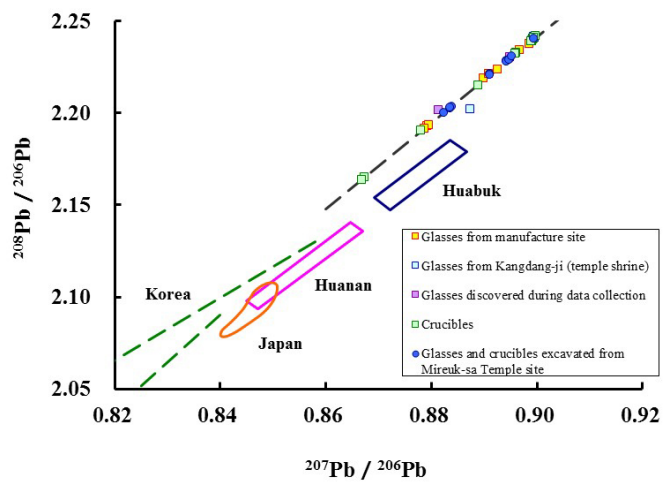

(a) ${ }^{208} \mathrm{~Pb} /{ }^{206} \mathrm{~Pb}-{ }^{207} \mathrm{~Pb} /{ }^{206} \mathrm{~Pb}$

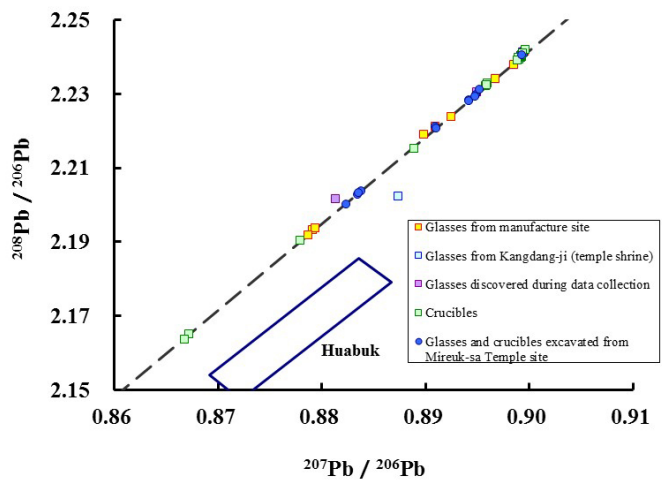

(b) Scale up (a) type

Figure 7. Lead isotope ratio $\left({ }^{208} \mathrm{~Pb} /{ }^{206} \mathrm{~Pb}-{ }^{207} \mathrm{~Pb} /{ }^{206} \mathrm{~Pb}\right)$ for glasses and crucibles excavated from Wanggung-ri and Mireuk-sa Temple sites. 
overlap of each other within the margin of errors. Also, MR2, MR6 and MR3, MR4, MR7, MR10(crucible), MR11(crucible) matched within the margin of errors. MR5 was located a little far from the group. The distribution of analyzed samples shows that identical raw materials were probably used for the glasses and crucibles from Mireuk-sa Temple.

\section{CONCLUSION}

In this research paper, I presented the basic information for glass production and distribution in ancient Korea based on our analysis of glasses excavated from the Wanggung-ri site. However, lacking comparison data and having only few researchers in this field, we could provide only limited historical information at this point. We hope that our research will be a starting point for further study in the future that will provide more diverse researches in this area.

\section{ACKNOWLEDGEMENT}

This work was supported by the research grant of the Kongju National University in 2018. We also would like to thanks co-workers of lead isotope ratios analysis, Dr. Hirao Yoshimitsu and Dr. Ro Jihyun.

\section{REFERENCES}

Brill, R.H. and Wampler, J.M., 1967, Isotope studies of ancient lead. American Journal of Archaeology, 71(1), 63-77.

Brill, R.H., Yamazaki, K., Barnes, I.L., Rosman, K.J.R. and Diaz, M., 1979, Lead isotopes in some Japanese and Chinese glasses. Ars Orientalis, 11, 87-109.

Han, M.S. and Kim, S.J., 2015, Provenance study on ancient lead glass relics using a lead isotope ratio. Journal of the Mineralogical Society of Korea, 28(2), 187-193. (in Korean with English abstract)

Kang, H.T., Kim, S.B., Huh, W.Y. and Kim, G.H., 2003, Application of science for interpreting archaeological materials (II) - production and flow of lead glass from Mireuksa temple -. Korean Journal of Cultural Heritage Studies, 36, 241-266. (in Korean with English abstract)

Kim, G.H., 2002, A study of archaeological chemistry on ancient glasses found in Korea. Doctor's thesis, Chungang University, Seoul. (in Korean with English abstract)

Kim, G.H., Han, S.H. and Kim, N.Y., 2006, Scientific analysis of artifacts excavated from Iksan Wanggungri ruins, Iksan Wanggungri excavation interim report 5. Buyeo National Institute of Cultural Properties. (in Korean)

Kim, N.Y., 2013, An investigation of chemical characteristics on alkali glass beads at the Three Kingdoms period in Korea, Doctor's thesis, Kongju National University, Gongju. (in Korean with English abstract) 